University of Michigan Law School

University of Michigan Law School Scholarship Repository

Articles

Faculty Scholarship

2011

\title{
An Old-Fashioned View of the Nature of Law
}

James Boyd White

University of Michigan Law School, jbwhite@umich.edu

Available at: https://repository.law.umich.edu/articles/2108

Follow this and additional works at: https://repository.law.umich.edu/articles

Part of the Legal Profession Commons

\section{Recommended Citation}

White, James Boyd. "An Old-Fashioned View of the Nature of Law." Theoretical Inquiries L. 12, no. 1 (2011): 381-402.

This Article is brought to you for free and open access by the Faculty Scholarship at University of Michigan Law School Scholarship Repository. It has been accepted for inclusion in Articles by an authorized administrator of University of Michigan Law School Scholarship Repository. For more information, please contact mlaw.repository@umich.edu. 


\title{
An Old-Fashioned View of the Nature of Law*
}

\begin{abstract}
James Boyd White ${ }^{* *}$
The law is a not an abstract system or scheme of rules, as we often speak of it, but an inherently unstable structure of thought and expression. It is built upon a distinct set of dynamic and dialogic tensions, which include: tensions between ordinary language and legal language; between legal language and the specialized discourses of other fields; between language itself and the mute world that lies beneath it; between opposing lawyers; between conflicting but justifiable ways of giving meaning to the rules and principles of law; between substantive and procedural lines of thought; between law and justice; between the past, the present, and the future. Each of these tensions is present whenever a lawyer or judge goes to work. None of them can be resolved by resort to a rule or other directive, but must be addressed anew by the lawyer and judge in each case as it arises, by the exercise of an art of language and mind that is defined by the nature of these tensions themselves.
\end{abstract}

\section{INTRODUCTION}

As some of you may know, I have spent a lot of energy in the course of my career trying to connect the western literary and humanistic tradition with the teaching and study of law.

To some people this work has naturally seemed a bit puzzling, even idiosyncratic. "What can literature possibly have to do with law?" is a question I have been asked over and over. From my point of view, such a questioner often misunderstands what literature is, and can do - maybe seeing it only as a form of aesthetic consumption, not as about anything

* This Article is based on the third Annual Cegla Lecture on Legal Theory, delivered at Tel Aviv University Faculty of Law on March 4, 2010.

** Hart Wright Professor of Law emeritus, Professor of English emeritus, formerly adjunct professor of Classical Studies, The University of Michigan. I want to thank Jeanne Gaakeer, Jefferson Powell, Joseph Vining, and Mary White for helpful criticisms of an earlier draft. 
important except the pleasure it gives - and much of my writing has been aimed at correcting this kind of misjudgment.

But I think such a questioner also often misunderstands what law is, and can do, or at least understands these things differently from the way I do, and it is mainly law that I wish to talk about here. My idea is to render more explicit than I have done so far the vision of law itself out of which I have been functioning: what I call in my title an old-fashioned view of the nature of law.

What I shall say, in a phrase, is that law is not at heart an abstract system or scheme of rules, as we often think of it; nor is it a set of institutional arrangements that can be adequately described in a language of social science; rather, it is an inherently unstable structure of thought and expression, built upon a distinct set of dynamic and dialogic tensions. It is not a set of rules at all, but a form of life. It is a process by which the old is made new, over and over again.

I think I can best give content to this perhaps puzzling summary by explaining where the view I describe comes from. This will require me to be a bit autobiographical, but I hope you can see that here my real subject is not me, but the law.

\section{Law as an Activity of Mind and Language}

I came to law from the study of English literature and Classics, especially ancient Greek. In both of these fields my focus was on language, most obviously so with respect to Greek.

In working on Greek I naturally asked questions like the following: How was this language put together? What were its key terms of value, of social and natural description, of psychology, and what did they mean? What were its principles of grammar and syntax, governing the way in which sentences could be composed? What were the forms of thought and imagination that this language invited and made possible? What, in short, could be said and done in this language that could not be said and done in English? (Do you see that the same questions could be asked of the law?)

The activity of translation, in which I was constantly engaged, captures the essence of the problem I was facing: How much, or how little, of what Homer does in the Miad, say, can be brought into English? When we try to bring this poem into English, how do we distort or damage the original? How do we add to it?

I could see that I simply had to learn to read Homer in his language if I were to begin to understand what he said and did. 
As I did that, what did I begin to see or experience? Certainly not what might be called an art-object, as some might think, offering itself to our aesthetic delectation, as a fine wine offers itself to our palate. The Iliad is beautiful, but it is also hideous, and it certainly is not about beauty as an aesthetic ideal. The same I think is true as a general matter of virtually any imaginative literature worth reading.

What the Iliad offered, as I saw it, was an engagement with what seemed like everything: the way a culture (in this case the heroic culture it describes and celebrates) is formed and works; the nature of cultural imperatives, and the way they can lead us into war and murder; the way an individual, necessarily formed in large part by his culture, can find himself almost by accident, as Achilles does, suddenly on the edge of that culture, in a position from which it can be seen and in some sense criticized and resisted; the character of human life itself, bounded as it is by death; and the achievement of art, by which this universal fact of human mortality can to some extent be defeated.

As the French philosopher Simone Weil says, the Iliad is a poem of force": it shows us the roots of war in the ideologies by which we dehumanize each other - a dehumanization the poem itself heroically reverses, in seeing and bringing the audience to see, against the force of the military culture itself, the common humanity of Greek and Trojan.

So for me the Iliad was not literature as aesthetic consumption or display, but a powerful form of thought and education about the most important things in human life.

What I say of the Iliad was true in a general way of the best of the other books I read ${ }^{2}$ : they offered engagement with human thought of the deepest and best kind about the most important matters in our individual and collective lives. In the work I admired - from Virgil to Shakespeare to Jane Austen to Robert Frost - I found people talking as well as they could about what was most important to them, constantly confronting their own limits of perspective, of

1 Simone Weil, L'lliade, ou le poéme de la force, CAHIERS DU SUD, Dec. 1940-Jan. 1941, often republished since then.

2 The Aeneid, for example, about the immense value and terrible cost of the Roman Empire; Jane Austen's novels, about the art of judging others accurately and comprehensively by what they say (especially difficult when they speak in formal contexts, where pretense and evasion are so easy to achieve); Thoreau's Walden, about the relation between the individual mind and the natural world, the whole universe of energy and life in which we live; and so on and on, throughout the world that the writers of the western tradition have created. 
knowledge, of mind - and the limits of their language too. Reading these texts in this way was for me a school for thinking well, reading well, writing well, and always about what mattered most in human life. ${ }^{3}$ (Can you imagine that I would come to say the same thing about law?)

I went to graduate school in English literature, hoping to make a life out of this kind of engagement with the writing I loved, but I was disappointed, in part because to me this profession felt disconnected from what I thought of as the real world, and for that reason was, I thought, unable to respond deeply and well to the texts to which it was supposed to be devoted. I may have been wrong, but this is what I felt, and I left for law school.

In law school I felt that I came back to my own mind, and to a life I recognized. I was learning law, a new language, a language in which to think about and debate many of the most important questions of our shared existence. It was like learning Greek, except that I was learning it for use in the world, rather than as a way of engaging with literary and philosophic texts.

This was not for me an academic or purely intellectual activity, but training in a profession that I intended to practice. I thought of this future most readily in rather small-town terms: I could imagine a client coming in off the street with a problem - a sense of threat or frustration or loss - that he or she could not handle without help. Law was the language into which this problem would have to be translated: it was the language I would use to define the problem and to make sense of it, and of its larger context too. It would ultimately be a language of power, producing a result authorized and enforced by the government.

The questions for me were these. What is this language of the law, and how does it work? What can be said and done in this language that cannot be done in ordinary English? How, in particular, does law work as a process

3 To take Jane Austen's novels as an example, she helps us deal with the fact that we live in a world of false speech of many kinds: sentimental, authoritarian, ideological, racist, dominated by hype and buzzwords and sales-pitches, by the beating of war drums. How are we to make our way in such a universe? This is what Austen tries to teach us, by exposing falsity and emptiness, manipulation and brutality, for what they are, and offering us forms of thought and speech that are genuine, powerful, and true. Her books offer an education in the difference between false and true, living and dead, in both thought and speech. 
of translation: with what losses, what gains, what distortions? ${ }^{4}$ What will it mean to me to give myself the mind and character of a lawyer?

As I imagined it, in practice I would be talking about what really mattered, in competition (and cooperation) with others who were doing likewise, before judges who were also talking about what really mattered. For what we were talking about was important not only to our clients, which it surely was - would they be compensated for their injury, or hold on to their land, or lose their inheritance? - but to the world: and this not so much because the outcome of the particular case mattered, but because it always matters very much to the world how such cases are debated and resolved. Every case performs an answer to the questions: What are our institutions of justice? How well - how justly - do they work? How should they work? And nothing is more important to a healthy community than justice.

I saw the law as a wonderful system in which power worked through conversation, through open argument and persuasion. In principle at least, everyone got his or her opportunity to present the case in the best way possible, and to answer what was said on the other side. In a legal hearing one could say whatever it was necessary or crucial to say about this injury, this divorce, this failed agreement, this event in the real world. ${ }^{5}$

To engage in this complex activity it was crucial that I should be able to learn and speak and use the language of the law well, and in two senses: that I should be an effective counselor and advocate; and that in doing so I should conceive of myself as doing something of value not only to my client but to the world: contributing to the maintenance of our institutions of justice, indeed contributing to the realization of justice itself.

Of course, as in all language use, all translations, I could see that the conversation of the law would always be imperfect: there would always be something left out, something out of tune, something stuck in, always a deep imperfection. Sometimes I thought that the legal language I was given to use was itself hopelessly dead and inadequate. Even where it did seem to have wonderful resources, these were not always taken advantage of by

4 I was later to pursue at some length the idea that law was a form of translation, in James Boyd White, Justice as TransLation (1990).

5 If a case was to be settled by negotiation, the hearing still remained the model of legal expression, because at every stage the lawyers were imagining that the case would proceed to trial and thinking ahead of time of the arguments that would be made both ways. Even in drafting documents the same was true: the lawyers were always testing what they were writing by imagining a dispute in court. 
lawyers and judges - who sometimes spoke in the dead ways familiar to all of us, full of clichés and empty formulas.

But both things - the inherent failings of the language and our failings in our use of it - seemed to me to present challenges for a life of value, the aim of which was to define and express meaning: the meaning of the experience of our clients; the meaning of the collection of authoritative texts and traditions and understandings that are the embodiment of the law; the meaning of the institutions of thought and argument in which these questions were presented and addressed. ${ }^{6}$

When I went into law practice the view I describe was confirmed: the heart of my work was reading and writing, not in a trivial or mechanical sense, not as the exercise of skill alone, but as the fullest and most important expression of a mind engaged in the world. It was hard to do it well, impossible to do it perfectly.

My view of law was internal, from the inside, from the point of view of someone actually doing it. The law can of course be looked at from the outside too, by sociologists and political scientists and anthropologists and others, and they are entitled to look at it differently: as a social or political process, or as a structure of rules reflecting certain policies. But the way they look will define what they see, and it will not be the law as I know it. They will not be doing law, but something else entirely.

I saw law, as I continue to see it, as an activity of mind and language: a kind of translation, a way of claiming meaning for experience and making that meaning real. It is not a system of rules, as I said earlier, but a structure of thought and expression built upon a set of inherently unstable, dynamic, and dialogic tensions. In this it is like a poem.

So for me law was a language that one could learn, well or badly, a structured activity of mind one could perform well or badly. One could use this language to carry on conversations in the world, conversations that produced results in the form of judicial decisions, settlement agreements,

6 I have spoken of the life of the lawyer as one of writing, but it was of course one of reading as well. One had to learn how to read texts written in other times and places, on other occasions, by other people, and bring them intelligently and coherently into the present, so that they might speak to the difficulty or dispute we were facing. This kind of reading, like the writing, was an ideal task that could never be performed perfectly, requiring imagination, learning, and intelligence, all of the highest order. And even with all the talents in the world, the coherence would still be imperfect, the argument flawed, the understanding incomplete - a fact that for me opened up a future full of great interest and value. 
contracts, and the like; results that mattered, sometimes acutely to actual people, especially the clients; and results that mattered in another way to the whole polity, for one question always present in the conversation was what justice should require, what the law should be. The object of our work was to reconstitute the material of the past to claim new meaning in the present and future.

\section{Tensions in Legal Thought and Expression}

Exactly what are the tensions of which I speak, and how do they work? How are they to be addressed? What does it mean that the law is built upon them? These are my next questions.

I should tell you at the outset that much of what I am going to say about them may seem very basic. Indeed it is basic. At one time perhaps we could even have taken much of what I am going to say for granted. At the time when I was a student and a young lawyer this set of perceptions might not have been wholly conscious, but I think it was there in the legal culture, and did not need stating. This is why I call it an old-fashioned view of law.

\section{A. Between Legal Language and Ordinary Language}

It may help us uncover some of the tensions upon which legal discourse is built if we think of a day in the life of the lawyer I was preparing to become, starting with the moment when the client comes into our office seeking our help.

This client - whether a person or corporation or government body will have a story to tell and a language in which to tell it. Perhaps he will tell us about domestic violence that he or his children have suffered; perhaps about an idea that he and two others have for forming a corporation that will create and sell computer software; perhaps about the bank's threat to foreclose the mortgage on his house.

The problem can be mundane and ordinary, or sophisticated and rare, but in any case our client will have his own sense of what is wrong, of what he wants, and of his own incapacity to get it on his own. He will turn to us, after all, only when he sees that he needs help.

His story will be cast in his ordinary language, the way he usually thinks and speaks. Our job is to listen to him talk in his language, and then to ask questions that will prompt him to say more. For our knowledge of the law should enable us raise issues that he will not have thought of, and in this way encourage a fuller statement of his story in the language of the law. 
When is his story complete? When do we have everything we need to know? A very good question. The sea of possibly relevant facts is infinite, and there is no clear way of knowing when we have enough. In such conversations there is a circular dependence between facts and law: the facts determine what law is relevant, the law determines what facts are relevant. ${ }^{7}$ In principle we could go on forever, but we stop when we think we have enough to enable us to develop his case.

No rules could tell us when we have reached this point; our sense of completeness is a judgment we gradually make, as we go back and forth between his story and what we know of the law. It rests upon our educated intuition.

Our second task will be to translate what we have been told by our client into legal language. This requires us to go from his or her language to the law and back again, over and over, checking both his story and our translation of it. As with all translations, this process is inherently imperfect and distorting. It cannot be done to a formula or rule, but requires the exercise of an art.

Sometimes the gap between our languages seems on the surface rather small, for example at closing argument, when we are speaking to the jury and do so in a language as close to ordinary English as we can manage. ${ }^{8}$ Sometimes the gap is enormous. When our client hears us make an argument about choice of law - maintaining, for example, that Nebraska law should apply, not Iowa law, or federal law rather than state law - she may not see any connection at all with the problem she brought to us. But the choice of law problem, if it is a real one, is one of the ways the law gives meaning to her case. It may even be that what this case will ultimately stand for in the law is a new and persuasive approach to choice of law, something she may not care about at all.

Our first tension in the law, then, is the one between ordinary and legal language. The lawyer has to speak both languages; he or she has to translate, as well as possible, both ways, into the law and out of it, a process that is at every stage defective or imperfect. Sometimes the defect will be fatal: we

7 I owe this observation to Professor Albert Sacks, who made this illuminating comment in a classroom more than 45 years ago.

8 This appearance can be illusory. Beneath the surface of ordinary English one can often discern important legal judgments and arguments. 
will simply not be able to say in the language we are given what we think should be said about this case. ${ }^{9}$

This tension can be found not only in interviews with the client, but throughout the process, and in many forms: in the lawyer's examination or cross-examination of lay witnesses, for example; in her closing argument to the jury, who are of course untrained in the law; and even in her arguments with the opposing counsel and to the judge, for it is common there to resort to ordinary life and language for images with which to make a point. Everyone wants to be able to say in ordinary terms what she is saying in legal terms, and vice versa.

This tension is made more difficult by the existence of a related one, between language of any kind at all and the mute world of inexpressible experience. In an important sense the client's story can never fully be told even in ordinary English. There is always a level of experience that cannot be adequately expressed in any language: what a broken arm actually feels like, for example, or the helpless rage and agony of seeing your children hurt by your spouse, or the mute sense of outrage or betrayal at a business partner's disloyalty. Everything that we say, in any language, floats as it were on a sea of inexpressible experience.

So we face not only a tension between legal and other forms of language and expression, but a tension between the world of words and the world of mute experience that underlies it.

These tensions are inherently unstable, never fully resolvable. Responding to them is not a matter of logic, or ends-means rationality, or conceptual analysis, but requires an art, an art of language and judgment.

9 In such a case we are effectively silenced. I discovered this when I represented a young man who refused induction into the armed services on the ground that the compulsory medical treatment he would receive in the service would violate his religious beliefs. He was not a draft dodger, but a kind of misfit in the law. I imagined myself making a grand argument to the jury, urging them to do justice to his case, but then realized that under the relevant statute the only question before the jury would be whether he had refused induction. The issue of the propriety of his draft classification was for the court, which was in fact required to affirm if the classification was supported by any basis in fact. If the case had gone to trial I would have nothing at all to say to the jury. For more about this case, see JAMES BOYd White, The Legal Imagination 187-95 (1973). 


\section{B. Between Law and Other Languages}

The tension between legal and ordinary speech is an instance of a larger tension, our second, arising from the fact that legal discourse is itself built upon many different voices, many different languages. It speaks not with one voice but with many voices, and its meaning to a large degree lies in the music that is made among them.

Thus in my country, for example, we have the official voices of the legislature, the trial judge, the Constitution, the Supreme Court, each speaking in its own way to the others, and to the public too.

We also have witnesses, expert and inexpert, each speaking from his or her point of view in the world. The voice of the person who saw the robbery, of the policeman who investigated it, of the technician who tested the blood, of the robbery victim himself; the voice of the defendant, of the psychiatrist testifying on the question of his sanity, of the witness who claims he saw the victim begin the fracas by attacking the defendant; all these are different voices, speaking in different languages.

Suppose for example that our case is a medical malpractice case, in which each side plans to call two expert witnesses - a heart surgeon, say, and an engineer who knows about mechanical heart valves. To prepare our own witnesses for direct and cross examination, and to cross examine the opposition witnesses, we shall need to learn something of the languages of the doctor and engineer. We must be prepared to translate, that is, not only between ordinary language and legal language, but between both of these languages and a range of specialized languages. ${ }^{10}$ This activity of translation is both necessary and inherently imperfect, and what it requires in us is the exercise of an art.

It is sometimes thought that the law is a single language of authority, a set of nested commands, running from the general to the particular, all in the same voice of absolute or legislative authority, but as we see here such a view makes little sense. The lawyer or judge must be an artist in translation, prepared to translate between the world of mute experience and the world

10 An obvious difficulty is that we cannot really learn the language of the doctor or engineer with the kind of completeness and depth that only those professionals can have. How then do we face this impossible task? Partly, we are schooled by our own witnesses, and by other advisers as well; partly, we read in the field in question to learn its language as well as we can; partly, we test, over and over, what the expert says by translating it into ordinary language that we can understand. 
of words; between ordinary language and legal language; and between both of these and specialized languages as well.

Perhaps we do not teach translation of this kind in law school but we certainly should. ${ }^{11}$

\section{Between the Opposing Lawyers}

There is a third tension, very different in kind, that is also fundamental to the legal process: the tension that exists between the lawyers on opposing sides of the case. This tension is plain: we want our client to win, he wants his to win, and each of us will do all we properly can to make that happen.

Thus at trial each lawyer will stretch every nerve to present the material of the law, and the facts, in such a way as to fit with the fundamental claims of his client. One is the voice of condemnation or attack, the other of excuse or defense. We are deeply opposed, for each of us is straining to create a sense of the case, and the law, that will lead the judge or jury to decide our way. This is a power struggle in the law, and it creates an inherently unstable tension, one that is by nature both dynamic and dialogic.

Yet there is something odd here: while we and the lawyer on the other side are obviously opposed to each other, we are also in fact cooperating. We agree in a general way, for example, both about the materials of our argument and the way it should proceed. While we are strenuously disagreeing, that is, we are equally strenuously affirming a great deal: the language, the conventions of discourse, the principles or understandings by which we carry on our argument, and certain conclusions too, on questions both of law and fact. We contest what we can, but we accept what we cannot, and this becomes, for the moment at least, a firm foundation for further thought on both sides. We thus affirm the very constraints of the law within which we find that we, despite our strongest efforts, must operate.

When our joint performance works well — as it of course does not always do - it subjects the material of the law, and the facts too, to the most intense and searching scrutiny. Instead of seeking the single meaning of the statutes, of the judicial opinions, of the regulations, and of other materials of authority, we two lawyers together are demonstrating the range of possible meanings that these texts may be given, and using all our powers to do so.

11 For an account of a course that attempts to do some of this, see James Boyd White, Translation as a Way of Understanding the Language of the Law, in ORDINARY Language and Legal Language 61 (Barbara Pozzo ed., 2005). 
In our hands, that is, the law is not a closed system of significances, but is systematically opened up to new possibilities - opened up, in fact, as far as we can do it. That is one of the points of our work.

This tension between competing voices and perspectives gives a special kind of life to the law. As I just said, it creates a space for newness and creativity in reading the texts of the law, which might otherwise be read in dead and mechanical ways.

It is also a way of being grown-up: learning to live in a world in which people think differently from each other and to respect the judgments of those with whom we disagree.

This very process, rhetorical and adversary in nature, creates a related tension, an internal one, moral or ethical in nature, within each of the lawyers. Is what she is doing justifiable, or even respectable?

We are making arguments for our client, on the law and the facts; but suppose we do not think that what we are arguing for is right? Suppose we think that the other side should win? Or, perhaps more likely, suppose we do not allow ourselves to think at all about the right result, about what justice requires, but only about what arguments will work? What have we become?

This problem can be swept under the rug by claiming that the adversarial system works to produce justice, so that even if we are not arguing justly, the system will be just - if not in this particular case, most of the time. But that claim rests on an unprovable optimism, and in any event does not address the most important ethical issue, which is who are we becoming when we engage in the activity I describe. Are we just mouthpieces who will say anything to win, whether or not we mean it? Or can we see ourselves as doing something we can truly respect?

A book could be written about this issue, ${ }^{12}$ but I hope that you can already see that here is another tension, inherently unstable, deep within the lawyer himself or herself. It is unavoidable by a conscientious person. It is not susceptible of systemic resolution, by resort to a slogan or a rule or a phrase, but must be addressed over and over in the life of the lawyer, in the deep particulars of every argument he or she makes.

12 For my own efforts at dealing with this problem, see JAMES BOYD White, WhEN Words Lose Their Meaning ch. 4 (1984); and James Boyd White, Heracles' Bow ch. 9 (1986). 


\section{Between Competing but Plausible Readings of the Law}

For our next tension, let us assume that the efforts at negotiation have failed and that the case is headed for court, where the two lawyers will speak to the judge who will decide between them.

If we imagine ourselves for a moment as the judge, we can see that the tension between the lawyers creates, or ought to create, a parallel tension in our own mind, as the two opposing voices are present and alive within us. If we start to think one way, we should find ourselves checked by the other way of thinking.

The elaboration by the lawyers of arguments on both sides is a way of resisting the judge's impulse to decide too quickly, encouraging her to keep her mind open until she has heard it all, thought through it all — indeed helping her to think it through.

The two sets of arguments, in making explicit the range of possible choices open to the judge, make clear that the judge will have to make her choice and accept responsibility for it - not push the decision off on a statute or other text that is read in a conclusory or unthinking way.

This argumentative process makes plain that the image of the law as a set of clear (and perhaps even self-applying) rules cannot survive a moment's scrutiny. Under the pressure provided by the lawyers' arguments, the scope of judicial choice becomes wide, much wider than one would at first expect. This fact creates a tension right at the heart of the judicial judgment, a tension between rational but opposed conclusions. This is our fourth tension.

If a statute says that "trucks" must travel in the right lane, or that imported "toys" pay only half the usual customs duty, or that an arrest may only be made upon "probable cause to believe the suspect has committed a felony," we have a general idea what is meant to happen, but we also know that elaborate arguments can go about the meaning of the words, truck, toy, probable cause, felony, and even commit (does it include aiding and abetting another, or being an accessory after the fact?).

Legal categories, whether legislative or judicial in origin, thus invariably carry a substantial range of reasonable possibilities for their meaning, sometimes a very wide range. Among these possibilities the judge will have to choose. How is she to do this?

A great deal has been written on this question, with answers ranging at least across the following spectrum: (1) the uncertainty of meaning creates in her a discretionary power to do whatever she wants; (2) she is to be guided in the exercise of her discretion by her sense of the intention of 
the rule-maker; (3) she is to be guided by appropriate general principles of moral and political philosophy; (4) she is to be guided by natural law; (5) she is to be guided by analogy to other legal examples; (6) she is to resolve the ambiguity against the drafter of the document, since he or she is responsible for it; and so on.

I will not join in the debate as to which of these, or others, should guide her decision. It is enough for present purposes that it is clear that in her basic task of legal decision the judge inhabits a zone marked by a strong tension between alternative ways of thinking, a tension that is, like the other ones I have described, dynamic, dialogic, and inherently unstable. The resolution of this tension, like the other ones, cannot be achieved simply by reference to a rule or practice or phrase or idea, but must be achieved afresh, in every case, by an art of judgment. This very fact gives life to the law.

As the judge faces this problem, she also faces her own version of what I called before the tension between the world of language and the world of inexpressible experience. This tension arises within her the moment she asks herself how and why the case should be decided.

Here is what I mean. A part of her mind will think in terms of legal arguments of the kind we have been discussing, testing them against each other for their force and power. But beneath that layer of the mind is another, an intuitive center, educated by experience and reflection, that is really seeking the right decision. The judge knows that her written opinion can never express or justify what the center of herself is doing, the secret spring of judgment at her core. ${ }^{13}$ This tension cannot be resolved in any a priori way by a rule or principle, but must, like the others mentioned, be lived through in detail and addressed anew every time.

\section{E. Between Substance and Procedure}

A fifth structural tension runs through the law: between what we call "substance," on the one hand, and procedural or institutional considerations on the other.

One of the deepest - and to the lay person, most mystifying characteristics of legal thought is that the lawyers and judges seem to

13 The opinion therefore, however honestly written, has some of the characteristics of a false pretense: This is why I decided the case as I did, the opinion says; but the judge knows that the true springs of decision are deep within her, and can never be fully known or explained. This is another tension inherent in the legal process. 
think about both kinds of questions at once, working as it were in two channels simultaneously. Whenever the lawyers argue about a substantive question, such as the meaning of a statutory or constitutional provision, they are likely at the same time to argue about a procedural question: the requirements for a judgment on the pleadings, for example, or for summary judgment, or for a directed verdict.

This second channel, which I am calling "procedural," is by no means limited to technical matters of judicial procedure, but includes argument of a much more general kind, which might be called "institutional."

Suppose the substantive question is whether one may dump industrial waste water in the river; or whether a school on an Indian reservation may begin its days with the recitation of a sentence that sums up the traditional wisdom of the tribe; or whether one may have a loud party to celebrate one's child's graduation from school, even though the neighbors object. The lawyer or judge facing such substantive questions will at the same time face a set of institutional questions: Who is empowered to decide this question in the first instance, and why? What procedures should this actor be compelled to follow, and why? To what review is the first actor's judgment to be subjected, and why? Or, to reverse the point of view, to what degree of deference is it to be entitled, and why?

Suppose, for example, in the water discharge case that there is a municipal ordinance on the subject. Here the lawyers will ask what I have been calling the substantive question - whether the ordinance should be interpreted to prohibit this discharge — but at the same time a set of institutional questions: whether the city council was authorized to pass such an ordinance by the relevant statute; if so, whether it followed the requisite procedures; if so, whether this ordinance, even if authorized by statute, meets the requirements of the state or federal constitution. In fact much of what we mean by constitutional law is institutional in just this way, determining what agency should have the power to decide what questions, under what procedures, and subject to what review.

The mind of the lawyer and judge mysteriously works in both tracks at once, and there is an inherently unstable tension between them. Sometimes, indeed, the two lines of thought intertwine in such a way as to make them one. We just cannot think of one without the other. What happens in one line of thought affects the other. It is like seeing that the smooth and rough sides of a piece of cloth each require and imply the other.

There is no way to draft a set of rules for resolving this tension. It must be addressed by an art of language and judgment. 


\section{F. Between Law and Justice}

A sixth tension, still different from the others, exists at the heart of legal thought, between the twin demands of law and justice. For in our system the lawyer and judge alike must ask not only, "What does the law require?" but "What does justice require?"

It is a convention of our law - which I have never seen plainly stated, but it seems to me undeniable - that in every case the lawyer on each side must maintain that the result he or she is arguing for is both required by the law and itself fundamentally just. An argument claiming that the law requires the outcome, but admitting that the result is unjust, would be profoundly incomplete. No lawyer would want to be in the position of making such a case. Likewise incomplete would be the sister argument claiming that justice requires the result argued for, but admitting that the law is against it. Nor would a judge happily admit either that her judgment was unjust or that it was against the law.

In this sense ours is a system of both natural and positive law. It is like a chariot being drawn by two horses: they often pull in opposed directions, but unruly and uncooperative as they may be, together they take the chariot in a direction that is much better than that towards which either of the horses alone is pulling it.

The immense and deep tension between these two claims means that the lawyer or judge must often labor to harmonize them, sometimes to the breaking point. But it also gives both lawyer and judge an opportunity to create something new and alive: not merely the logical working out of rules or premises, but a deep engagement both with the texts of the past and with the facts of the present, and what they mean. It is one aspect of the lawyer's great task, which is to bring into one field of vision the ideal and the real. ${ }^{14}$

14 Consider, for example, the fact that we talk to the judge not as the bundle of prejudices and beliefs and commitments and character traits that form part of his or her character, but as an ideal judge, one who is always seeking to do justice under the law. Likewise, we idealize the legislature, interpreting its words as if they came from a wise and good person, when of course the truth is more complex. We also idealize our client in the way we talk about him, presenting him in the best light possible. In this sense we are engaged in work that is explicitly aspirational in character.

At the same time we are required to be realists, about all these actors and about the process too, recognizing that the legislature is a political body, that the judge is biased for us or against us, that our client has all the usual faults of humanity: he may lie to us, or not pay the fine, or our bill; he may even skip town. 


\section{G. Between the Past and Present - and the Future Too}

Finally let me suggest one more tension, a temporal one: between the past and the present, and between both of them and the future. ${ }^{15}$

The task of the lawyer and judge is to bring the materials of the past sometimes recent past, sometimes remote past - to bear on the problems of the present, and in so doing to make something new for the future. The law is thus not a static or timeless system, working out the implications of its premises in abstract or purely logical ways, but a way of functioning in a world dominated by time, seizing the ever-passing moment of the present as the place to join past and future. It is a way of defining experience; learning from experience; shaping experience.

This tension is present in all legal argument, but most of all in the special form we call the judicial opinion. This text brings together all that the parties have been able to invoke from the past, and issues the authoritative judgment that speaks to the future.

\section{The Writing Life of The LaWyer And Judge}

I am saying, then, that legal thought is not the top-down elaboration of the meaning of a set of rules, by a process of logic or end-means rationality; nor is it a pattern of conduct that can be adequately represented and understood in the language of social science; rather, it is an activity of mind and language, one that is deeply marked by a set of structural tensions (or clusters of tensions):

- between ordinary language and legal language (indeed between language itself, of any kind, and the mute world that lies beneath it);

- between a multiplicity of voices, speaking from different positions within the legal order, or outside of it, in a variety of specialized and expert languages;

- between the two lawyers, each of whom seems to resist the other at every point, though in another way they are cooperating deeply; and within

15 Here are two others one could add to the list: the tension between narrative and theory in the mind of the lawyer or judge (for these modes of thought work in very different ways); and the tension between the particular and the general, a feature also of poetry and other forms of literature. For further discussion, see WHITE, supra note 9 , at 858-926, 624-86. One might also consider the special set of tensions that the legislator must face as he or she gives shape to a statute, discussed in the same book. Id. at 195-242. 
each lawyer, whenever she asks what it means for herself and the world that she is acting as she is;

- between many conflicting but justifiable ways of giving meaning to the rules and principles of law, among which the judge will have to choose; and also between the reasoning and intuitive capacities of the judge herself;

- between substantive and procedural (or institutional) lines of thought, a tension that runs throughout the law;

- between the imperatives of law and justice; and

- between the past and the present, the present and the future, for law lives in time and out of shared experience.

This is not an exhaustive list, but for present purposes it will do.

Each of these tensions is, as I have said, inherently unstable, that is, not resolvable by reference to fixed rules, principles, or conventions; each is dynamic, not static, thus moving us in new directions that we cannot always anticipate; each is dialogic, not monologic, thus acting with the force of competing voices at work in the world or in the self. These tensions interact, to create fault lines that run through every act of full legal analysis. Their management is essential to the work of lawyer or judge.

\section{A. The Law Is Not the Rules}

What happens if we start to think of law in this old-fashioned way?

Let me suggest, to start with, that it makes simply impossible the view that the law is a system or scheme of rules that are in practice applied more or less rationally to produce a set of intended or desired results.

This is a view that law students often bring to law school with them. They expect that we shall teach them a set of rules. These are the rules they will apply as lawyers, and knowledge of them is what sets them apart from the non-lawyer, to whom they are unknown. A large part of a good legal education is disabusing them of this view.

There are many reasons that such an image is attractive to the student. It explains the kind of knowledge that the lawyer has, and justifies his role (and his fees). It is also in principle simple, even easy: if all I have to do is memorize a set of rules, even if there are a lot of them, I am confident that I can do it. The work may be dull, but it won't be hard. It won't ask of me what I cannot already do; it will not ask me to change and grow. So it is natural for the student to say: "I want the law to be a set of rules!"16

16 It was once common for law teachers to think that one of the structural tensions in the classroom was over this issue, as, against resistance, we insisted that we were 
But I think the view of law as rules is also at work in the kind of scholarship and teaching that takes as its subject the question, not how lawyers think and should think, but what the rules should be. We see this view at work in policy studies generally, in law and economics in particular, in much jurisprudence, and indeed wherever the tendency to abstract or theoretical thinking has taken hold, whether in the analysis of legislative or judicial problems.

\section{B. The Law Is Not Policy}

The question of policy is of course a legitimate one, and lawyers, economists, social scientists, moral philosophers, ordinary people, and lots of others too, can properly speak to it.

But it is not the essential question for either lawyer or judge, who is instead repeatedly asked to deal with the particulars of a case, whether as adviser, advocate, or decider, and to do so in light of the whole structure of arguably relevant and authoritative legal rules, principles, conventions, precedents, understandings, indeed in light of the whole legal world and culture. This structure, as I have been trying to show, is not a coherent conceptual system but a dramatic and rhetorical process marked by a series of deep and inherently unstable tensions that cannot be reduced to or governed by a system of rules or other directives. ${ }^{17}$

Policy analysis typically assumes that the law consists of a set of rules that work more or less well, and that what matters is the content of those rules. Everything else is just noise in the system, of no real interest. Of course rules of the standard legislative (or judicial) form do exist, and they serve to guide general expectations and behavior. They are important and can be talked about in such terms. But this is not the level at which the judge or lawyer works, for they are normally called upon only when there is a problem or difficulty, a moment at which the rules collide with reality, or each other, and do not work in the easy way they are thought to do. To put it in a phrase, the judge and lawyer deal not with the "rules" as such,

doing something other than teaching rules, namely how lawyers think, and think well. In teaching criminal law, for example, I handed out on the first day a page which had on it all the rules we would learn that term. I told the students that they could memorize them in an hour at most. What this meant was that whatever the rest of the course was about, it was not learning the rules.

17 For a similar argument from a different point of view, see A.W. Brian Simpson, The Common Law and Legal Theory, in OXFORD ESSAYS ON JURISPRUDENCE, SECOND SERIES 77 (A.W. Brian Simpson ed., 1973). 
as a discrete conceptual system, but with what happens when that abstract language, and the rest of the authoritative language of the law, meets the world. From the point of view of the lawyer and judge, the law is not reducible to rules reflecting policy choices, but is an activity of mind and judgment that is vastly more complex, and more interesting, than such an understanding would suggest.

\section{The Law Is a Set of Possibilities for Original Thought and Expression}

The law is not a system, but a way of managing the relations between what looks like a system and many dimensions of actual life: the experience of the client and lawyer, including the experience that cannot be expressed in any language at all; the multiplicity of languages and voices that make up our world; the conflicts and harmonies between opposing lawyers; the freedom and responsibility of the judge; the idealistic and realistic tendencies of legal thought; the tension between past and present, present and future.

The way in which lawyer and judge think about the moment at which the language of the law meets the world is to engage in a complex process of thought that is built upon and marked by tensions of the sort I have summarized. ${ }^{18}$ These cannot be resolved by reference to any set of directives or guides, but must be addressed afresh whenever the lawyer or judge goes to work, and always in light of the particulars of the case in which they are presented. The lawyer and judge do not operate simply at the level of high generality that the rules mark out, nor simply at the level of particularity established by the facts of the case, but always in an uneasy tension between these two levels of thought. They are in this like poets, who also face the tension between the particular and the general in all that they do. ${ }^{19}$

18 This is true of the teacher as well, of course. When I think of my own decision to teach law rather than practice it, and of the claim, by some, that this is a retreat to the Ivory Tower from the Real World, I want to say that teaching, properly done, is itself a form of practice, a way of facing the set of tensions I describe here. To do this one must regard the cases not simply as instances of theoretical questions or the application of rules, but as pieces of the whole process of legal argument and thought, as I have sketched it here, from the interview with the client right through to the appeal of an adverse judgment.

19 Sir Philip Sidney said that philosophy deals with mere abstractions, history with mere particulars; the poet alone "doth . . . perform both." SIR PHILIP SIDNEY, THE DEFENSE OF POESIE (1595), available at http://www.bartleby.com/27/1.html. In law as in poetry, the life and quality of one's work inhere in the way in which constraints are faced, tensions addressed and elaborated, complexities recognized. This must be done every time afresh. Think of the way a poem is built: it is a structure of meaning 
In saying all this, let me stress, I am trying to define what I see to be the possibilities of life in the law. Of course these possibilities are not attained automatically, and never fully or perfectly, and sometimes they are corrupted. Often lawyers and judges are thoughtless, crude, unimaginative, inarticulate, and dull. Indeed such things are sometimes true of us all. But not always, and not in every way. My effort here is to offer an image of the activity of law by which we can shape our efforts as we practice or teach it, an image, over the horizon, as it were, which we can keep before us as we do our work: a sense of how things might be if only we could make them so.

The law does not work its way to predetermined conclusions through a process of iron logic, but almost the opposite: it is a set of possibilities for original thought and expression. It is not a totalitarian system, closed and unlistening, but an open system, like a language, not only making creativity possible, but requiring it. The process in which we are engaged is an art of testing and invention.

Every case, every legal conversation, is an opportunity to exercise the lawyer's complex art of mind and imagination. This art is what we teach, what we practice, and what we cherish.

\section{The Law Is an Art of Mind and Language}

In calling what the lawyer and judge engage in an art, I have in mind the thought that all art — whether music or painting or architecture or poetry or drama - proceeds by way of tension and resolution: a conflict is stated or hinted at or felt; the tension between opposing elements is developed and expanded; and at the end a resolution is reached - but never a final resolution, only a momentary one. When one poem or sonata is finished, another is to be begun, and so it is with legal argument and legal judgment. The aim of the lawyer, as for the poet, to quote Robert Frost, is to end "in a clarification of life - not necessarily a great clarification, such as sects and cults are founded on, but in a momentary stay against confusion." 20

The tensions I have been defining are not, then, as some might say, simply "noise in the system," but the life of the law itself.

in which many dimensions, each one built on tensions of its own - image, story, meter, rhyme, sentence shape, and so on - interact to create a living whole. Legal work is like that.

20 Robert Frost, The Figure a Poem Makes, in Robert Frost: Collected Poems, PROSE AND PLAYS 776, 777 (Richard Poirier \& Mark Richardson eds., 1995). 


\section{Conclusion}

If I am right, what I am saying here has real consequences: for the sort of education that we offer, which should invite the student to engage in the art I describe, not to learn law as a set of rules; for the ethical and intellectual possibilities of the lawyer's life, which can be seen to be far more interesting, challenging, and ethically alive, than the view of the lawyer as rule-applier; for the expectations that judges can bring to their work and for the ways in which we can evaluate what they do — not simply by political agreement or disagreement with the outcome, but by judging their work as performances of an art, the art of reconciling the ideal and the real.

This vision of the law is indeed an old-fashioned one, going back to the roots of legal thought in the west, in the study and practice of the art of rhetoric. At its heart it is a vision of law as an art, an art of language and judgment, an art of the maintenance and repair of human community. In another sense, however, it is not old-fashioned at all, but as timely as it ever was. In my view it is necessary to have such a vision if, in our practice and teaching and judging, the law is to fulfill its nature and its promise. This is, perhaps, "an old-fashioned vision of the law for the twenty-first century."

I have been resisting an image of law as rules and policy, but behind those things is a deeper vision: of law as abstract, mechanical, impersonal, essentially bureaucratic in nature, narrowing rather than broadening the human capacity for experience, understanding, imagination, and empathy. To focus on the law as a system, and not on what happens when that system meets the world - and the people of the world - is to strip it of its difficulty, its life, its meaning, and its value.

For it is at this moment, when the law meets the world - in the work of lawyer, judge, or teacher — that it becomes most fully alive. This moment contains within it the seeds of resistance to the forces of mindless empire and control, for every case is an opportunity for newness of thought, for creativity and surprise, for the introduction into the world of power an unrecognized voice, language, or claim.

In the moment of speech, or writing, there is always the possibility that one can bring the world into new life. 